\title{
EL EMOTIVISMO LIBERTARIO Y SUS SECUELAS
}

\author{
LA LIBERTAD, SIN EL REFERENTE DE LA CONDICIÓN HUMANA, CONVIERTE LOS \\ DESEOS EN DERECHOS
}
Francisco Bobadilla Rodríguez
Universidad de Piura
francisco.bobadilla@udep.pe

Fecha de recepción: agosto de 2014 Fecha de aceptación: octubre de 2014

Resumen: Este trabajo presenta una propuesta de comprensión de la crisis ética que anida detrás de una serie de reivindicaciones que parten de la libertad y buscan convertir ciertas apetencias en derechos. Existe un trasfondo antropológico que privilegia los deseos y niega la posibilidad de una naturaleza humana capaz de perfilar la andadura de las personas. Junto a los ya estudiados ídolos del poder, el dinero, la fama y el placer, nos parece que existe un nuevo ídolo, el emotivismo libertario. Este nuevo ídolo es el común denominador del actual divorcio unilateral, de los continuos

* Francisco Bobadilla Rodríguez es magíster en Derecho, con mención en Derecho Civil, por la Pontifica Universidad Católica del Perú, licenciado en Ciencias de la Información por la Universidad de Piura y candidato a doctor por la Universidad de Zaragoza (España). Sus temas de estudio se centran en el aspecto antropológico, ético y jurídico de la conducta humana. Ha colaborado en diferentes publicaciones como la revista Istmo de la Universidad Panamericana de México y en la Revista Mercurio Peruano Ha publicado Pasión por la excelencia (Lima: CAME, 1999); Empresas con alma (Piura: Universidad de Piura, 2002) y El Código Da Vinci: de la ficción a la realidad (Lima: Realidades S.A., 2006). Actualmente, es vicerrector adjunto del Campus Lima de la Universidad de Piura y director de Centro Cultural Universitario Sama. 
intentos de despenalizar el aborto y de los proyectos alrededor de las uniones civiles. Se ha elegido una perspectiva filosófico-antropológica. De esta forma se ubica como el referente moderno por excelencia a Jean Jacques Rousseau $y$, aun cuando en el legalismo liberal el triunfo fue de Thomas Hobbes, en el vitalismo emotivista el gran triunfador póstumo es el primero: el buen salvaje redomado no soporta ni los límites de la ley ni los de la condición humana. Hecho el diagnóstico, la sugerencia es colocar, nuevamente, a la libertad en el conjunto de los radicales de la existencia humana. Una libertad que abrace la verdad del ser humano en toda su extensión y profundidad. La libertad huérfana de la verdad de la naturaleza humana no hace más que empobrecer la realidad humana.

Palabras Clave: emotivismo, liberalismo, universidad, derecho, Jean Jacques Rousseau, Thomas Hobbes.

\title{
THE LIBERTARIAN EMOTIVISM AND THEIR AFTERMATH
}

\section{FREEDOM, WITHOUT REFERENCE FROM THE HUMAN CONDITION, MAKES}

\section{DESIRES RIGHTS}

\begin{abstract}
This work presents a proposal for understanding the ethical crisis that lies behind a series of claims that are based on freedom and searching to transform certain rights appetites. There is an anthropological background that favors the desires and denies the possibility of a human nature capable of shaping the walking of individuals. Along with previously studied idols of power, money, fame and pleasure, it seems that a new idol, the libertarian emotivism. This new idol is the common denominator of the current unilateral divorce, continued attempts to decriminalize abortion and projects about civil unions. Has chosen a philosophical-anthropological perspective. In this way it ranks as the modern benchmark for excellence
\end{abstract}


is Jean Jacques Rousseau, and even when the liberal legalism was won by Thomas Hobbes, in vitalism emotivist the big posthumous winner is the first: the good downright wild supports neither the limits of the law or the human condition. Made the diagnosis, the suggestion is to place again, freedom in all the radicals of human existence. A freedom that embraces the truth of the human being in all its breadth and depth. Orphan freedom of the truth of human nature does nothing more than impoverish human reality.

KEYwords: emotivism, liberalism, university, law, Jean Jacques Rousseau, Thomas Hobbes.

\section{INTRODUCCIÓN}

aber mirar lo que está debajo de la punta de un iceberg requiere un especial esfuerzo para adentrarse en su base, cual las raíces del tronco y sus ramas. Hace cien años, Víctor Andrés Belaunde leyó la lección en el inicio del año académico en la Universidad Nacional Mayor de San Marcos. Al comenzar su discurso, el ilustre pensador peruano dijo lo siguiente:

[...] la altísima misión moral de la Universidad solo puede realizarse uniendo su vida a la vida nacional, y planteando en las aulas los problemas esenciales del país. Tal idea indujo a sabios maestros a estudiar, en esta ocasión solemne, las cuestiones patrias de interés palpitante con criterio científico y con absoluta sinceridad. Acatando una sabia disposición reglamentaria, y 
procurando continuar en la medida de mis fuerzas esa tradición honrosa, quiero tratar de la cuestión que a todos inquieta, de la crisis actual, crisis intensa que, con repercusiones en el orden económico, se halla en la esencia de las instituciones políticas y tiene sus causas profundas en el desquiciamiento moral (Belaunde 2014:129).

Partiendo de dicha afirmación, puede rastrearse la inquietud de aquel intelectual por ver más allá de los problemas estructurales o técnicos. Aunque no sea fácil analizar fenómenos tan complejos, el resultado vuelve sobre un tema pendiente como es la moral. Gracias a esto, la gran intuición de Víctor Andrés Belaunde fue señalar que «todo fenómeno económico encierra un fenómeno político y que todo fenómeno político envuelve una cuestión moral»(Belaunde 2014: 130).

El problema del Perú, el del 2015, no es el que aquejaba al Perú de Víctor Andrés Belaunde. No existe crisis económica. El país es una isla envidiable de la aldea global planetaria. El crecimiento económico del Perú de los últimos diez años está preñado de esperanzas. Hay todavía mucho pan que rebanar, es verdad, pero lo cierto es que los indicadores de desarrollo humano cada año son más favorables. La inclusión social es un largo camino pero es clara la toma de esa ruta. La atención no estará fija, por tanto, en los índices del desarrollo económico, pues el interés se centrará en las variables culturales, aquellas que son familiares a los que ejercen el oficio universitario. En esta materia, la responsabilidad que compete abordar es muy grande.

Crisis económica, afortunadamente, no. Lo que existe por delante son, en cambio, tambores que anuncian una crisis moral. A la universidad, cuna de las artes liberales y areópago del cultivo de la sabiduría, le compete la reflexión profunda de los caminos que va tomando la cultura. No se trata de 
tener en ella un rol de simples espectadores. Existe el deseo de formar parte de su curso y que la impronta humanista y cristiana acompañe los afanes de los hombres y mujeres que labran día a día el mejor futuro a desear.

Una de las más grandes autoridades morales de este siglo, el Papa Francisco, ha señalado los siguientes tres innegables ídolos que oscurecen la plenitud de la condición humana: (a) el poder, (b) el dinero y (c) el placer. Los siguientes juicios emitidos por el Santo Padre son contundentes:

La crisis actual no es solo económica y financiera, sino que tiene sus raíces en una crisis ética y antropológica. Seguir los ídolos del poder, del provecho, del dinero, por encima del valor de la persona humana, se ha vuelto una norma básica de funcionamiento y el criterio decisivo de la organización. Se ha olvidado y se sigue olvidando que por encima de la lógica de los negocios, de la lógica y de los parámetros del mercado, está el ser humano y que hay algo que es debido al hombre en cuanto hombre, en virtud de su dignidad profunda: ofrecerle la posibilidad de vivir con dignidad y de participar activamente en el bien común. Benedicto XVI nos ha recordado que todas las actividades humanas, incluyendo la económica, precisamente porque es humana, debe ser articulada e institucionalizada de manera ética (cf. Encíclica Caritas in veritate, 36). Por lo tanto, tenemos que volver a la centralidad del hombre, a una visión más ética de las actividades y de las relaciones humanas, sin el temor de perder algo. (Francisco 2013a: párr.6) ${ }^{1}$

1 Con parecidas palabras se dirigió a los jóvenes de la JMJ 2013 de Brasil: «Es cierto que hoy en día, todos un poco, y también nuestros jóvenes, sienten la sugestión de tantos ídolos que se ponen en el lugar de Dios y parecen dar esperanza: el dinero, el éxito, el poder, el placer. Con frecuencia se abre camino en el corazón de muchos una sensación de soledad y vacío, y lleva a la búsqueda de compensaciones, de estos ídolos pasajeros. 
El Estado, el mercado y los medios de comunicación son los grandes protagonistas del mundo contemporáneo. Aunque aparecieron como creaciones humanas pensadas para servir a los ciudadanos, sin embargo, los elementos que las distinguen ( (a) poder, (b) dinero y (c) persuasión, respectivamente), hoy resultan ser tremendamente cuestionados. Al conjunto de los tres, la sociología alemana las llama tecnoestructura. Inquieta, entonces, comprobar cómo (a) el poder (el Estado), (b) el dinero (el mercado) y (c) la persuasión (los medios de comunicación) transcurren tantas veces, no solo a espaldas de la sociedad civil, sino, incluso, en contra de ella. Es una realidad que dichos elementos de esta tecnoestructura han silenciado la voz de la sociedad, otras veces manipulan la realidad e ignoran el clamor de la ciudadanía que pide a gritos participación social. Todos ellos han sido creación del ser humano para servirlo, pero por esas paradojas de la vida de las que los tiempos actuales están inundados, han crecido cancerosamente, arrojando de su seno a sus creadores.

El gran olvidado en este engranaje tecnocrático es el ser humano en sus gozos y esperanzas, tristezas y angustias. Falta el teatro de la historia del género humano marcado por sus destrezas, sus derrotas y sus victorias (cf. Vaticano II). Es el espacio en donde se tejen las relaciones interpersonales, es irreductible al poder, al dinero o a la persuasión. Edmund Husserl llamó a este espacio existencial lebenswelt (el mundo de la vida), es decir, el ámbito en el que el ser humano se encuentra de modo espontáneo. Citando a Carlos Llano, se trata de «Una verdadera sociedad subterránea [...] agobiada por las reglamentaciones estatales, por las presiones mercantiles y por la invasión de los medios de comunicación» (Llano 1999: 135). Este ethos vital referido Queridos hermanos y hermanas, seamos luces de esperanza. Tengamos una visión positiva de la realidad. Demos aliento a la generosidad que caracteriza a los jóvenes, ayudémoslos a ser protagonistas de la construcción de un mundo mejor: son un motor poderoso para la Iglesia y para la sociedad» (Francisco 2013b: párr.4) 
posee una endémica resistencia a someterse al mundo de la racionalidad moderna. En el ámbito del Estado, rige la reglamentación; y en el mercado, la ley casi matemática que ordena las complejas vinculaciones de la oferta y la demanda. Pero en el lebenswelt hay inconexiones, agitación de elementos que se asientan aleatoriamente por el procedimiento de la coctelera, ante el que no caben las predicciones racionales sino la paciente espera para ver cómo quedan.

La mujer y el hombre de a pie no sienten vinculación ni representación alguna en el poder, ni en el mercado ni en los mass media. Ante esto, la pregunta es obligada, ¿qué puede hacerse desde una universidad para revertir esta situación? ¿Qué puede hacerse, entonces, para que los profesionales estén en condiciones de poder resistir al canto de sirenas que escucharán (poder, dinero y persuasión), al precio de traicionar la propia excelencia? En sí puede hacerse mucho, pero también es evidente que no se trata de ocuparse por un asunto técnico. Frente a lo más delicado del oficio universitario, la integridad personal, es necesario dotar a los alumnos las competencias éticas necesarias que los ayuden a resistir en el bien, a no cansarse de hacer el bien. La universidad tiene que ser la fuente que fortalezca el mundo de la vida, aquel de las relaciones interpersonales, la reciprocidad y la confianza.

La presión de la tecnoestructura sobre el mundo de la vida es muy fuerte. La política formal, aquella cuyos rostros serán los llamados poderes del Estado (Poder Judicial, Ejecutivo y Congreso), alcanzan niveles mínimos de aceptación y niveles máximos de rechazo. En el mercado, el dinero compra voluntades y destroza la honestidad. Los medios de comunicación muestran una agenda que no se corresponde con la agenda ciudadana, despreciando, incluso, el buen juicio del poblador peruano. No hace falta insistir más en 
el reconocimiento de estos males que aquejan a la tecnoestructura social. Asimismo, las voces de alerta contra los ídolos que han generado poder, dinero y placer han sido lúcidamente puestos en evidencia. En las palabras que continúan, se pondrá la atención en un nuevo ídolo, propuesto así, a falta de mejor denominación, como el emotivismo libertario. Cuya presencia estará decididamente presente tanto en la legislación actual como lo es el divorcio unilateral, el actual debate de la unión civil y el del aborto, todos ellos discutidos en el presente trabajo. Lo que sigue es apenas un somero esbozo de lo que se intuye como uno de los mayores rasgos deficitarios de la cultura contemporánea.

\section{LA LIBERTAD INFLAMADA}

Aquel emotivismo libertario se asienta, como tantos hallazgos de la aventura humana, en un radical constitutivo de la persona: su libertad. Un bien valiosísimo, cuya conquista personal y social es tarea de toda una vida. Desde niños, sin saberlo aún, se busca ser libres. El pequeño, a la primera de bastos, intenta hacer por sí mismo sus primeros pinitos. Tan pronto consigue moverse, ya desea caminar por cuenta propia y se desprende de las manos de papá o mamá. El desarrollo humano continúa con esa trayectoria y al adolescente le falta tiempo para correr por cuenta propia sin las trabas de sus padres. Liberación, autonomía, autorrealización, libre desarrollo de la personalidad, elección, decisión, entre otras, son caras del poliedro de la libertad. Sin embargo, cabe recordar lo que José Ramón Ayllón reconoce como su carácter instrumental y finalidad refiriéndose a que la libertad:

[...] está al servicio del perfeccionamiento humano. Los colores y el pincel están en función del cuadro; la libertad está en función 
del proyecto vital que cada hombre desea, es el medio para alcanzarlo. Por eso la libertad no es el valor supremo: de hecho, nos interesa en la medida en que apunta a algo más allá de la libertad, algo que la supera y marca su sentido: el bien. (Ayllón 2012: 24)

Podría afirmarse que el problema, por tanto, no es la libertad, sino la inflamación de esta. Se trata, pues, de una libertad desbocada, tirada hacia adelante, sin más norte o brújula que el mero querer, sin padre, ni madre, ni genealogía, es decir, la abstención de otros radicales constitutivos de la condición humana. Para continuar manejando esta denominación, se optará por ahondar en ella en las siguientes líneas.

Para una libertad de estas características, todo es historia y devenir, creación artificial humana que hoy se presenta y mañana se quita. No existe lo estable, no hay algo presente que deba reconocerse como previo y desde lo cual deba construirse. A esta libertad inflamada le molesta y le incomoda el límite y lo dado, pero lo cierto es que para correr a la velocidad que al individuo se le antoja, se necesita de la autopista e ir siguiendo su curso y al cabo de un tiempo, debe frenarse ya que la autopista ha llegado a su fin. El sano sentido común, la sabiduría del campesino de los andes, el arte del obrero de construcción, conlleva a saber que el agua hervida quema, que las heladas matan a las plantas y que no hay edificios altos sin buenas columnas y vigas. Saber estos temas elementales, conocidas muchas de ellas a simple vista o por la experiencia, es simplemente tener buen juicio. Creer que puede prescindirse de la realidad del frío, del calor, de la resistencia de materiales, del colesterol malo, de la presión sanguínea alta es, simplemente, necedad.

De plantearse más interrogantes, estas serían ¿se puede jugar fulbito con una pelota de vóley? Sí, pero el precio de tal aventura es que al término 
del partido, la bola de vóley queda inservible, si es que antes no se rompe. ¿Por qué se ha destrozado? La respuesta es obvia, porque dicho balón no está diseñado para jugar fulbito. El ser humano pasa por circunstancias parecidas, con la salvedad de que a diferencia de la bola de vóley cuyo deterioro es inmediato, el cuerpo y el espíritu del ser humano pasan factura al mediano y largo plazo. Basta ir al médico cuando se padece una dolencia para percatarse de esa aplastante realidad. El diálogo será previsible, ya que el médico diagnosticará: «lo que usted tiene ahora, señor mío, se debe a los desarreglos alimenticios de su juventud». El enfermo en su defensa dirá: «pero, doctor, si yo siempre he comido carnes rojas». La conversación terminará con la sentencia médica: «pues, a partir de ahora, ya no puede comerlas». Los ejemplificaciones sobran y la conclusión es muy sencilla: «no puedo comer lo que me da la gana, no, por lo menos sin poner en riesgo mi vida».

\section{LA REBELIÓN CONTRA LA CONDICIÓN HUMANA}

A esta realidad inapelable de la condición humana, el pensamiento clásico la llamará naturaleza humana, es decir, aquello dado en el ser y hacer del hombre y la mujer. ¿Puede obrarse en contra de uno mismo? Sí, pero al precio de estropear lo que se es, del mismo modo que la pelota de vóley se malogra después de un partido de fulbito. Ahora es más que pertinente lo que Albert Camus, escritor francés, Nobel de literatura de 1957, dijera, de una manera exacta y lacónica, en cuanto a que «el ser humano es el único que puede ir en contra de sí mismo» (Camus 2003: 18).

De esta forma, puede percibirse que, detrás de algunos de los problemas que oscurecen la imagen del ser humano, está, precisamente, este emotivismo libertario, una inflamación de la libertad que se niega a reconocer 
la realidad de la condición humana so pretexto de ganar mayores espacios de libertad. Desde esa mirada, son reconocibles algunos debates actuales. Estos vendrían a ser el llamado divorcio unilateral, introducido en el Código Civil peruano en el 2001, los ataques al derecho a la vida a través de la legislación permisiva del aborto y, ahora, el proyecto acerca de las uniones civiles, son todos ellos expresión de este nuevo ídolo.

Es menester volver nuevamente sobre la libertad y situarse en el siglo XVII. La situación en la que Rousseau ha dejado a la libertad y la ley es de una fragilidad tremenda. En la pugna entre libertad individual y ley, la balanza se inclina por la libertad emotiva, sin cabeza, siendo así puro corazón. El deseo quiere convertirse en derecho. Son las pretensiones de ciertos colectivos sociales que buscan el soporte jurídico a sus apetencias, desligadas de todo concepto de naturaleza humana. Deseo y libertad se fusionan, sensualidad y espiritualidad se superponen; el sentimiento opaca al pensamiento por lo que el discurso se carga de emotividad.

Anteriormente, Locke y Hobbes (Glendon 1991: 66) habían caracterizado al hombre en estado de naturaleza como un solitario. Rousseau agrega, además, que el buen salvaje es autosuficiente, «errante en las selvas, sin industria, sin palabra, sin domicilio, sin guerra y sin vínculos, sin necesidad alguna de sus semejantes, [...] sujeto a pocas pasiones y bastándose a sí mismo, no tenía más que los sentimientos y las luces propias de este estado» (Rousseau 1984: 97).

Se entiende, entonces, que en el paradigma liberal, la sociedad sea un fenómeno adventicio, una creación propia del estado de sociedad al que se llega por pacto. Allí, en la sociedad, el buen salvaje aprendería a sujetar y encausar su natural espontaneidad, aunque la sociedad no dejaría de ser un 
inevitable artificio. Es el reino del individualismo, muy bien descrito por Karol Wojtyla, ahora San Juan Pablo II, en las siguientes palabras:

[...] actuar junto con otros, es una necesidad a la que el individuo tiene que someterse, una necesidad que no corresponde a ninguna de sus propiedades positivas [...] Para el individuo, los otros son una fuente de limitación [...] Si se forma una comunidad, su propósito es proteger el bien del individuo del peligro de los otros. (Wojtyla 1982: 320)

Una libertad así entendida genera mónadas incomunicables, islas solitarias y desconocidas. Libertad como espontaneidad, por un lado, y fidelidad a una promesa, por otro, son un contrasentido. Un ser libre, solitario, individualista y autosuficiente no se ata a promesas. Con seres incapaces de comprometerse y movidos por su sola espontaneidad, no se puede hacer nada juntos, mucho menos una sociedad. Pero ese es el paradigma liberal y así llega el buen salvaje al estado de sociedad, sociedad que no puede ser sino acuerdo tácito de voluntades, un contrato, un pacto que genera obligaciones exigibles jurídicamente. Todo esto lo entendió muy bien Hobbes, de ahí que, para domar la espontaneidad del buen salvaje, optó por los lazos fuertes y seguros de la ley. De esta forma, el filósofo planteó un sistema jurídico, desde luego, entendido al modo liberal, un orden coactivo que hace previsible el futuro y tiene la suficiente fuerza para hacer cumplir las promesas y pactos.

El pacto social ha moderado el natural individualismo del buen salvaje, pero no lo ha eliminado. Está allí y al primer descuido salta, buscando recuperar el espacio perdido. La deriva a la libertad como mera espontaneidad es una constante en la sociedad presente. Cornelio Fabro 
dirá que esta libertad carece de fundamento trascendental, pues « [...] se ha constituido en objeto y fin de sí misma: se ha convertido en una libertad vacía, en una libertad de la libertad, ley de sí misma porque es libertad sin más ley que la explosión de los instintos o la tiranía de la razón absoluta, que se revela después como capricho del tirano» (Fabro 2002: 174).

En efecto, allí está la común raíz de dos rasgos aparentemente inconciliables de las sociedades modernas: el emotivismo y el funcionalismo racionalista. El funcionalismo racionalista y legalista pone orden a las emociones en su brote caprichoso (cf. Cipriani 2001). Sin derecho no hay promesa alguna que no sea más que un canto de cisnes en la sociedad liberal. De esta forma, todos, en gran medida, pueden calificarse de salvajemente roussonianos.

\section{EL EMOTIVISMO ROUSSIONANO}

La facultad de hacer promesas recorre toda la historia (cf. Arendt 1996). Ciertamente es así, aún continúa usándose el viejo aforismo romano pacta sunt servanda, acompañado de la fides romana, la lealtad a la palabra dada (cf. D’Ors 1977). Precisando aún más, es posible encontrarse con ello al dirigirse siglos posteriores de los latinos, cuando a inicios del XIX, en los albores del liberalismo contemporáneo, el Código Civil francés prescribe lo siguiente: «Los convenios legalmente formados tienen carácter de ley entre quienes lo celebraron. No pueden ser revocados sino por mutuo consentimiento o por las causas que la ley establezca. Deben ser ejecutados de buena fe» (Artículo 1134). Por el lado nacional, el actual Código Civil peruano, vigente desde 1984, establece lo que sigue: «Los contratos son obligatorios en cuanto se haya expresado en ellos» (Artículo 1361) y «deben negociarse, celebrarse y ejecutarse según las reglas de la buena fe y común 
intención de las partes» (Artículo 1362). El contenido es el mismo en ambos códigos y no podía ser de otro modo, ya que el Código Civil francés, de marcado corte patrimonialista, inspiró al peruano y a tantos otros que no hacían sino recoger los principios liberales triunfantes en la Revolución de 1789.

Sin derecho no existe, pues, promesa posible en la sociedad liberal. El derecho forma parte del funcionalismo racionalista sin el cual los engranajes de la sociedad no se moverían. Precisando aún más, el contrato se convierte en el instrumento que viabiliza la promesa. Ya no es en virtud de la voluntad por la que uno permanece fiel a lo prometido, sino que es el contrato el cual, desde fuera, ata y exige coactivamente el cumplimiento. Esta fuerza vinculante del derecho está tan metida en el imaginario de la gente que, sin ninguna duda podrían ser, al igual que la canción, "palabras, tan solo palabras», aquellas promesas que carecen del soporte de lo jurídico. Al hablarse de una madre, ella sabe muy bien que si el compromiso no se formaliza «ante Dios y el registro civil», se ha perdido el tiempo por más promesas hechas. Detrás de este proceder, está la idea de que la promesa solo adquiere consistencia y durabilidad cuando está de por medio el derecho. Por esta razón, a la novia se le llama "prometida», pues como estipula el Código Civil peruano, incluso existiendo la promesa recíproca de matrimonio es decir, la pedida de mano no existe la obligación de casarse con ella (Artículo 239). «Prometida» sin matrimonio y promesa sin contrato son como café descafeinado en la sociedad del bienestar.

En la sociedad liberal, el derecho se reduce a la ley, y la ley llama a más leyes, con lo que el derecho muta y se convierte en una realidad de menor entidad llamado legalismo. A pesar de la saturación de leyes y sus derivadas, finalmente es un mal necesario en una sociedad que ha renunciado 
a fomentar la vida buena de sus ciudadanos. Ha podido más el rigorismo de Hobbes que el republicanismo virtuoso de Rousseau, tal y como lo plantea Helena Béjar de la siguiente forma:

En el modelo espartano, Rousseau plantea magistralmente el núcleo del republicanismo: ¿Cómo puede llegar la ley al corazón de los hombres? Dicho problema tiene una resolución tan difícil, en política, como el de la cuadratura del círculo. Para Rousseau, la materia última de la política es afectiva. Ello permite entender al ginebrino como un demócrata radical y como un eslabón crucial en la tradición de la virtud. La unión entre política y sentimiento es parte de la herencia que Rousseau lega a los líderes de la Revolución francesa: «Los reyes y los aristócratas han desempeñado muy bien su oficio: ahora os corresponde a vosotros desempeñar el vuestro, es decir, hacer a los hombres felices y libres por medio de leyes» ¿Cuál es nuestro objetivo?, se preguntaba el Incorruptible: gozar pacíficamente de la libertad y la igualdad, implantar una injusticia eterna cuyas leyes hayan sido grabadas no en mármol o piedra sino en los corazones de los hombres. (Béjar 2000: 94)

\section{DIVORCIO UNILATERAL}

En el derecho liberal, el matrimonio es un contrato singular, pero, finalmente, es un contrato; es decir, manifestación de voluntades, sujeto por tanto a término, de acuerdo a las causales de disolución del vínculo matrimonial, tales como el adulterio, la sevicia, la injuria grave, etc., dichas causales que pueden ser invocadas por el cónyuge inocente para pedir la 
separación de cuerpos y el divorcio. Asimismo, se encuentran también la separación convencional. Hasta aquí, simplemente se presentan respuestas liberales basadas en la idea de que el matrimonio es asunto de dos, tanto para el acuerdo como para desacuerdo. Es en la dinámica del estado de sociedad donde la libertad del buen salvaje se torna libertad ordenada.

Pero estas ataduras no han resistido la fuerza de las apetencias y el buen salvaje hace nuevamente su aparición, despertado, esta vez, por el emotivismo reinante. Se trata de la introducción en el Código Civil peruano del llamado divorcio unilateral. ${ }^{2}$ Esta modalidad viene a ser la separación de hecho de los cónyuges durante un periodo ininterrumpido de dos años, al término de los cuales, cualquiera de ellos puede solicitar el divorcio. Esta nueva causal rompe con la idea del pacto entre dos; es tan feroz el individualismo que la nutre, que le da la facultad de deshacer el matrimonio, incluso, al cónyuge culpable, fundando su demanda en hecho propio. De esta forma vuelve a entrar por la ventana el concepto de libertad como pura espontaneidad, sin vínculos u obligaciones. Es la regresión al estadio del buen salvaje, solitario, independiente, autosuficiente, desvinculado.

Una situación así, ¿es tan solo una excepción, una anomalía aislada en el tejido social? No, es simple consecuencia de una de las derivas del liberalismo. La libertad roussoniana, tarde o temprano, tiende a sacudirse de los vínculos que la atan: no hay promesa ni virtud que aguante esta corrosión del carácter. El emotivismo del mundo de la vida sigue en ebullición y los deseos pugnan por convertirse en derechos. Es la voluntad de unos que

2 Art. 333, Inc 12 del Código Civil peruano, modificado por Ley 27495 del 7.VII.01: Entre las causas de separación de cuerpos, se menciona el inc 12. La separación de hecho de los cónyuges durante un periodo ininterrumpido de dos años. Dicho plazo sería de cuatro años si los cónyuges tuviesen hijos menores de edad. En estos casos no será de aplicación lo dispuesto en el Artículo 335 (ninguno de los cónyuges puede fundar la demanda en hecho propio). 
insiste en imponerse a la voluntad general. Ya no es un asunto de mayorías o minorías, ni mucho menos de racionalidad, es pura presión, la presión del buen salvaje roussoniano que busca recuperar su libertad desvinculada de la verdad de la condición humana.

\section{LA UNIÓN CIVIL ENTRE PERSONAS DEL MISMO SEXO}

Hacía mucho tiempo que no se producía un debate tan amplio en los medios de comunicación como el que ha suscitado el proyecto de ley sobre la «unión civil no matrimonial» para personas del mismo sexo. Al mismo tiempo, queda evidenciado que la opinión publicada en los medios no guarda proporción con la opinión pública, aquella del hombre y mujer que circula por las calles pavimentadas de las ciudades o los caminos de trocha del país profundo. La afluencia de artículos de opinión a favor de estas uniones civiles de los últimos meses parecería afirmar que todo el Perú está de acuerdo con ellas cuando la realidad es otra. Se calcula que más de un $60 \%$ de la población no acepta tal unión porque ve en ella una semejanza con el matrimonio que les resulta inadmisible.

La llamada unión civil solamente tiene de «no matrimonial» el título. Le interesa a esta propuesta mantenerse lejos de toda semejanza con el matrimonio, porque si así lo declarara la oposición sería aún mayor. Una amplia relectura de los diez largos artículos del proyecto, deja en evidencia el notable calco del régimen matrimonial tal como lo legisla el Código Civil peruano. Es decir, el proyecto del congresista Carlos Bruce de «no matrimonial» solo tiene esas dos palabras, su propuesta es una fórmula matrimonial vestida de unión civil.

Su semejanza con la unión de hecho es igualmente notoria (nótese art. 326 del Código Civil), pero, al igual que el régimen matrimonial, 
esta figura se asienta en la diversidad sexual de hombre y mujer (art. 5 de la Constitución Política del Perú). El proyecto Bruce le otorga, incluso, mayores derechos a los «compañeros civiles» que a los convivientes heterosexuales (por ejemplo, mayores facilidades para su reconocimiento). De ahí que, introducir la figura de las uniones civiles no sea solo agregar una nueva institución al ordenamiento jurídico peruano, sino, principalmente, rediseñar el modelo matrimonial peruano. El camino de la protección de los derechos patrimoniales y asistenciales de personas del mismo sexo no es el de la unión civil propuesta.

Una vez más, se presenta el emotivismo libertario que pone por delante el afán de autonomía y autorrealización, prescindiendo de toda referencia a la condición natural del ser humano. Se despoja a las personas y a las instituciones que desarrollan su humanidad, como lo son el matrimonio y la familia, de aquello que constituye su núcleo esencial, con la finalidad de dotarle carta de ciudadanía a una situación que, por darse de hecho, no necesariamente, se legitima como de derecho. $Y$ en este asunto, viene a su rescate el sano juicio de gran parte de la población peruana que rechaza estos intentos de equiparación. A aquellos «ilustrados», descalificadores de esta mayoritaria opinión pública opositora al proyecto en cuestión, tildándola de posición oscurantista y retrógrada, debería hacérseles notar que tamaña postura de la población es un verdadero repositorio de salud moral que la tecnoestructura no ha podido acallar. Más aún, se cumple a la letra la idea de que la custodia de los asuntos esenciales del buen vivir permanece en manos de la gente sencilla. Por esa razón, a) el poder, b) el dinero y c) la persuasión junto al emotivismo libertario no deberían despreciar esta sabiduría del sentido común. 


\section{EL PERMISIVISMO ABORTISTA}

El mayor de los males, si cabe, es sin duda el intento continuo de querer introducir en nuestro país una legislación permisiva del aborto. Un lobby de dimensiones mundiales que desconoce la condición humana del embrión, el gran ausente y la víctima por excelencia en el debate abortista. Es de esperar que, al igual que en los otros dos casos mencionados líneas arriba, esta, también, es una pretensión cuyo origen está en el emotivismo libertario, no en vano, el nombre con que se conoce a los defensores del aborto, es el de pro choice ('pro elección'), es decir, defensores del derecho de elegir que tendría la mujer sobre la vida o muerte del embrión. La condición humana del embrión, del niño en estado de gestación, pasa a un plano secundario. Pesa la libertad de la madre para deshacerse del niño durante el embarazo.

Si en el caso del divorcio unilateral es una de las partes la que decide terminar con el matrimonio; y en la unión civil, dos personas del mismo sexo eligen juntarse y equipar su unión a la matrimonial; en el caso del aborto, la elección sobre la vida de un inocente, es, indudablemente, la mayor pretensión que se pueda atribuir un ser humano de desnaturalizar la condición humana. La disponibilidad ya no solo versa sobre lo propio, sino que en el aborto se dispone, también, de la vida de una persona inocua. Son, asimismo, cruciales las palabras del Santo Padre Francisco cuando advierte: «Una sociedad que abandona a los niños y que margina a los ancianos corta sus raíces y oscurece su futuro» (Francisco 2013c: párr.4). 


\section{CONCLUSIONES}

Por ahora han sido utilizados tres ejemplos de nuestra cultura ilustrada ubicando una misma raíz: el emotivismo libertario, erigido como un nuevo ídolo. Y si lo que se acaba de exponer se puede tener como un diagnóstico de la situación cultural del momento, toca ahora a la universidad recuperar el sentido más profundo de la condición humana y sus rasgos primordiales, entre los que la libertad ocupa un papel protagónico. Una libertad que no bascule sobre sí misma, sino que abrace la verdad de la condición humana en toda su amplitud y profundidad.

Ignorar o rechazar la verdad de la naturaleza humana, es lanzarse a una aventura prometeica cuyo resultado no es ganancia, sino pérdida y empobrecimiento para el derrotero humano. Frente a los excesos en los que incurre el emotivismo libertario, es menester sumarse al gran esfuerzo intelectual que nos prepare a reconocer libremente la realidad de nuestro ser, imagen y semejanza del Creador. Es la tarea que le corresponde a la antropología cristiana a la cual, hoy más que nunca, le compete dialogar con esas otras propuestas culturales bien intencionadas, desde su posición que, en su intento de obtener el fuego de Zeus, tan solo consiguen hacer del ser humano un caña azotada por los vientos del desierto. 


\section{REFERENCIAS}

ARENDT, Hannah

1996 La condición humana. Barcelona: Paidós.

Ayllón, José Ramón

2004 Ética razonada. Madrid: Ediciones Palabra.

BÉJAR, Helena

2000 El corazón de la república. Avatares de la virtud política. Barcelona: Paidós.

Belaunde, Víctor Andrés

2014 La crisis presente 1914-1939. Lima: Universidad Nacional Mayor de San Marcos. 7. edición.

Camus, Albert

2003 [1951] El hombre rebelde. Madrid: Alianza Editorial.

Cipriani, Beatriz

2001 El tecnócrata moderno. Una mirada a la sociedad peruana. Piura: Ediciones Universidad de Piura. 
D’Ors, Álvaro

1977 Derecho Privado Romano. Pamplona: EUNSA.

FABRo, Cornelio

2002 El temple de un Padre de la Iglesia. Madrid: RIALP.

\section{FRANCISCO}

2013a «Discurso del Santo Padre Francisco a la Fundación "Centesimus annus pro Pontifice”». En La Santa Sede. <http://w2.vatican. $\mathrm{va/content/francesco/es/speeches/2013/may/documents/papa-}$ francesco_20130525_centesimus-annus-pro-pontifice.html >. Consulta hecha en $05 / 04 / 2014$.

2013b «Viaje apostólico a Río de Janeiro con ocasión de la XXVIII Jornada Mundial de la Juventud. Santa Misa en la Basílica del Santuario de Nuestra Señora de Aparecida. Homilía del Santo Padre Francisco». En La Santa Sede. <http://w2.vatican. $\mathrm{va/content/francesco/es/homilies/2013/documents/papa-}$ francesco_20130724_gmg-omelia-aparecida.html>. Consulta hecha en 19/05/2014.

2013c «Discurso del Santo Padre Francisco a los participantes en la Plenaria del Consejo Pontificio para la familia». En La Santa Sede. <https://w2.vatican.va/content/francesco/es/speeches/2013/ 
october/documents/papa-francesco_20131025_plenariafamiglia.html>. Consulta hecha en $13 / 05 / 14$.

Glendon, Mary Ann

1991 Rights talk. The impoverishment of political discourse. New York: Free Press.

Llano, Alejandro

1988 La nueva sensibilidad. Madrid: Espasa Calpe.

Llano Cifuentes, Carlos

1999 El postmodernismo en la empresa. México: Mc. Grow Hill.

Rousseau, Jean Jacques

1984 [1755] Discurso sobre el origen de la desigualdad entre los hombres. Buenos Aires: Editorial Orbis S. A.

VV. AA

1976-7 Código Civil de la República de Francia, de 21 de marzo de 1804. París: Dalloz. 6. edición. 
FRANCISCO BOBADILLA RODRÍGUEZ

VV. AA

2009 [1966] Constitución apostólica Gaudium et spes sobre la Iglesia en el mundo actual. Buenos Aires: Editorial Ágape.

VV. AA

2014 Código Civil. Lima: Jurista Editores.

WojTYLA, Karol

1982 Persona y acción. Madrid: BAC. 